\title{
Multi-Touch User Interfaces to Treat Social, Communicative and Collaborative Impairments in Children with Autism: A Review
}

\author{
Ahmed Hassan \\ Computer Software Engineering Department \\ University of Engineering \& Technology, Peshawar \\ Peshawar, Pakistan
}

\author{
Zeeshan Danish \\ Computer Software Engineering Department \\ University of Engineering \& Technology, Peshawar \\ Peshawar, Pakistan
}

\begin{abstract}
This paper concentrates in analyzing the paramount multitouch user interfaces that have been designed particularly to treat children having Autism. The proximity of these works with the due child computer interaction expertise is scrutinized; on the basis of which some significant findings are concluded. These concluded features are considered to be the success factors of these multi-touch user interfaces and future directions are given that act as a pilot study for researchers who aim to develop user-centered interfaces for treating social, collaborative and communication impairments in children with Autism.
\end{abstract}

\section{General Terms}

Human Computer Interaction, Autism Spectrum Disorder

\section{Keywords}

Child computer interaction, Autism spectrum disorder, social skills, collaborative skills, communication skills, multi touch, user interfaces, software applications

\section{INTRODUCTION}

Autism Spectrum Disorder or simply Autism is a term used for a range of neurological disorders that make the affected person hesitant of communicating, socializing and becoming friendly with people including their family, teachers and classmates [1].This habit makes them arrogant and lonely, which gains strength while they reach adulthood. Since, Autism symptoms usually appear in the very early age of 3 [2]; it needs to be treated well in time, to save a child's childhood and his later practical life.

Autism treatment naturally falls into a wide range of categories; few of these are Occupational therapy, Physical therapy, medical treatment and computer-based treatments [1]. Autism treatment falls into the domain of software engineering and Human-Computer Interaction when it comes to the computer-based treatment. In this regard, research is being conducted in robots, tangible user interfaces and multitouch based user interfaces to provide a smart environment to the child with Autism, for his improvement. This improvement is supposed to be in terms of his communication skills, social skills and collaboration with others as these are the areas where an Autistic child lacks. The primary concern of the current research, on a wider scale is to investigate the Be categorized into three classes of pedagogic UI design. We have reviewed three significant applications that aim to treat these three classes of impairments. These impairments and the work done in computer based interventions for the Autism Spectrum Disorder. Talking more specifically, we aim to scrutinize some of the most effective multi-touch applications that have been developed to target particular social impairments in an Autistic child.

Among the various treatment methodologies just discussed, multi-touch and tangible interfaces are enjoyed the most by children with Autism. This is so because these UIs are easier to use and there is wide room for accommodating lots of interesting features that could be helpful for these children. The prime objective of this research work is to investigate the multi-touch interfaces developed to treat certain social skills and to figure out the challenges still present for UI designers in terms of user-centered interface designing. With this, we try to analyze the extent to which the gap between UI development and HCI expertise has been bridged; and that what significant features do these UIs carry, and why. For this, the most relevant works have been investigated and future directions for UI designers specified.

\section{MULTI-TOUCH TABLES AND THEIR ROLE IN PROVIDING OPTIMIZED INTERFACE TO AUTISTIC CHILDREN}

The basic concern of all CCI-oriented interface designing is to make the UI simple yet interesting, so that the child user can learn something from it. Our concern is to specifically focus on a special group of CCI interface designers; i.e. UI designers who build multi-touch interfaces for children with Autism. In this respect, the review conducted in [3] was a recent and sound work to consider. The authors of this synthetic review have highlighted focal points about the available multi-touch hardware, as well as the related software - that we were interested in. since the authors were interested in investigating the pedagogic benefits of these multi-touch apps in a classroom environment, they conducted a project related to this.

\section{REVIEW METHODOLOGY}

Since the current research concentrates on user interfaces able to be used with multi-touch hardware and capable to provide effective learning to children with Autism, we deduce from [3] that most of the work done in this context, can generally relevant works we have analyzed have been summarized in Table 1. 
Table. 1 Impairments in a child with Autism and significant research work that targeted to treat these impairments

\begin{tabular}{|c|c|c|c|c|}
\hline S. No. & Use of multi-touch & \multicolumn{3}{|c|}{ Referred Work in the Autism domain: } \\
\hline & & App Name: & Authors: & URL: \\
\hline 1. & $\begin{array}{l}\text { Story-telling } \\
\text { activities }\end{array}$ & I Can Tell & $\begin{array}{l}\text { (Wadhwa \& Jianxiong } \\
\text { 2013) }\end{array}$ & $\begin{array}{l}\text { http://www.iosnoops.com/appinfo/i-know-quiz- } \\
\text { creation-app-for-ipad/570172763 }\end{array}$ \\
\hline 2. & $\begin{array}{l}\text { Collaboration } \\
\text { enhancement }\end{array}$ & Our Space & $\begin{array}{l}\text { (Rick, Harris et al. } \\
\text { 2009) }\end{array}$ & http://shareitproject.org/ \\
\hline 3. & Social interaction & $\begin{array}{l}\text { ECHOES } \\
\text { Serious Game }\end{array}$ & $\begin{array}{l}\text { (Bernardini, Porayska- } \\
\text { Pomsta et al. 2014) }\end{array}$ & http://echoproject.ca/ \\
\hline \multicolumn{4}{|c|}{$\begin{array}{l}\text { The three pedagogic apps mentioned in Table } 1 \text { and their user } \\
\text { interfaces will now be discussed, with special emphasis on } \\
\text { how these works have achieved an effective child-computer } \\
\text { interaction via their interfaces. } \\
\text { 4. I CAN TELL } \\
\text { The collaborative tablet application 'I Can Tell' is part of the }\end{array}$} & $\begin{array}{l}\text { f the final app. This is necessary, as mentioned in } \\
\text { ar work that over-burdening the Autistic subject with too } \\
\text { of responsibility ultimately frustrates him [5]. It is } \\
\text { ore essential to keep features for the child as well as his } \\
\text { / parent. This guarantees to maintain a trade-off in the } \\
\text { and his trainer/ parent's engagement while dealing with }\end{array}$ \\
\hline
\end{tabular}
work done by [4] in which they developed two I-phone applications namely I Know and I Can Tell. The heart of this work was to teach an Autistic child socialism, collaboration and better communication. The app under consideration, i.e. I Can Tell has a user interface that has been developed with due participatory design approach; it lets the child improve his communication skills via a story telling activity.

According to the authors of [4], participatory design is a plus point while designing interfaces for Autism treatment, because it lets the child involve in the design. It is thus a highly HCI-oriented design. We have therefore evaluated this work as being more adjacent to expertise in Child Computer Interaction than the other projects reviewed. In an attempt to reckon the causes behind this proximity in UI design and CCI expertise, the following aspects were jotted down as the success factors of this work [4].

\subsection{Iterative Participatory Design Development}

The authors of [4] have considered it necessary to include the parents, teachers or trainers in the design of their user interface; for they know better about the challenges their Autistic child is facing. For this, the authors used an iterative design scheme that ensured that after every successive iteration, the UI became more refined and fulfilled more needs of the Autistic subject. A diagrammatic representation of this method is shown in figure 1 .

\subsection{The Engagement Tradeoff}

The second key aspect shared by authors of [4] in their paper is about a balanced participation of the Autistic child in the

\subsection{Simplicity in the User Interface}

Apart from the two features discussed already, [4] have also pinpointed, based on their literature review, that too much simplicity and too much complexity are both dangerous when it's the matter of a UI for an Autistic child. These children happen to be temperamental and the UI should be carefully designed with emphasis on keeping things simple, up to a certain level.

\section{OUR SPACE}

Our space is an application based on a shared-space task [6]. The authors have used the diamond touch table to support this multi-touch user interface. The purpose of this application was to provide an environment of a virtual classroom with virtual students, and to let different Autistic children collaborate while trying to position the seats and students in this classroom. The significant features of this interface were that it supported multiple simultaneous touches, but at different portions of the diamond touch table. Also, a dragand-drop interface model was used to enable the children to easily place the icons (students) on certain positions.

It is customary to mention that the iterative design methodology adopted by [4] has also been used by [6]. This has been demonstrated by the UI designers of Our Space as they initially functioned a trial version of the application, after which they gathered the user experience and refined their interface. Table 2 shows the significant and profitable refinements that they made in their UI, as a result of their iterative

design. 


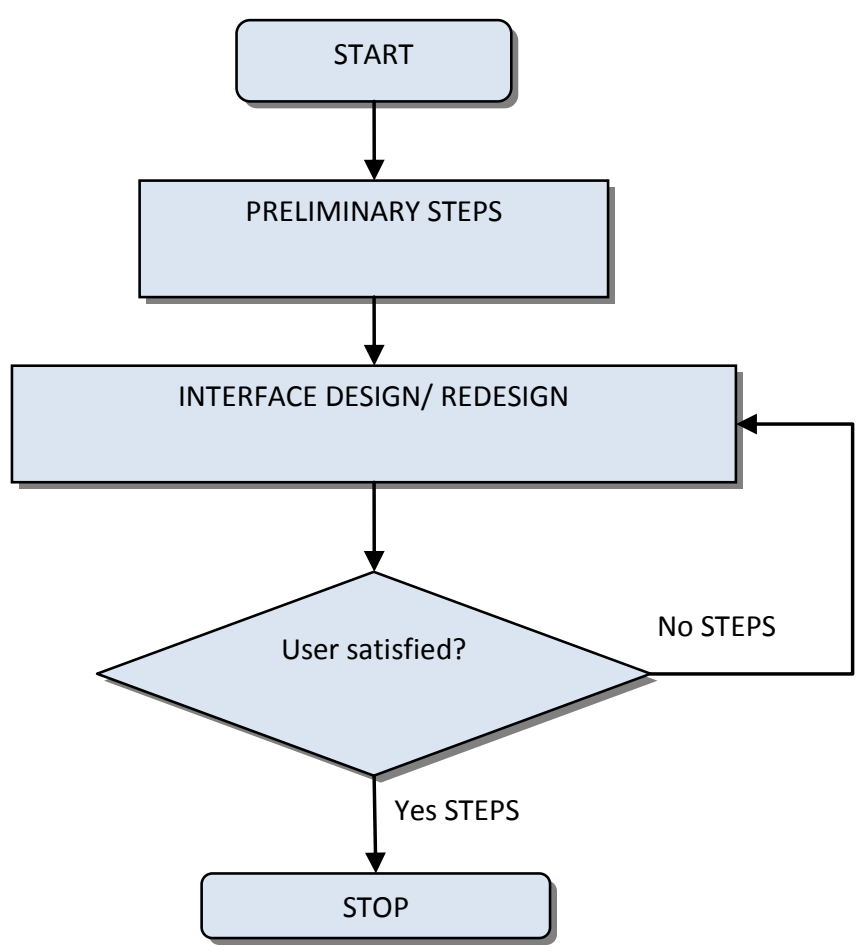

Fig 1: Flowchart of the iterative participatory design of interface designing

Table. 2 Results of iterative participatory design method when applied to the OurSpace application interface.

\begin{tabular}{|c|c|c|c|}
\hline Features refined: & UI attributes in trial version: & $\begin{array}{l}\text { Refined UI attributes after } \\
\text { iteration: }\end{array}$ & Illustration of the changes: \\
\hline Timing of rotation & $\begin{array}{l}\text { Desks were rotated every } 600 \\
\text { Ms. }\end{array}$ & $\begin{array}{l}\text { Desks rotation was } \\
\text { customized to achieve a } \\
\text { balance between too slow and } \\
\text { too fast, according to current } \\
\text { needs. }\end{array}$ & \\
\hline Seating snaps & $\begin{array}{l}\text { Very small seating snaps - } \\
\text { curbed to the desk area }\end{array}$ & $\begin{array}{l}\text { Larger snaps - children could } \\
\text { easily snap virtual students to } \\
\text { the desks now. }\end{array}$ & \\
\hline $\begin{array}{l}\text { Indication of students present } \\
\text { in classroom but not seated } \\
\text { yet }\end{array}$ & $\begin{array}{l}\text { Students standing and students } \\
\text { seated were represented in the } \\
\text { same way. }\end{array}$ & $\begin{array}{l}\text { Students standing and not } \\
\text { seated yet were shown with a } \\
\text { red circle to avoid confusion } \\
\text { to the users. }\end{array}$ & \\
\hline
\end{tabular}

\subsection{Findings}

The authors of [6] have conducted a healthy analysis of their developed application using ANOVA and MANOVA statistical analysis techniques. In a nutshell, their findings pinpointed first that the UI was more productive when used with multi-touch; also, it enabled the users (Autistic children) to collaborate well with multiple simultaneous touches together. Second, the single-touch version (implemented using a software based switch between single and multi-touch) was 
fine with adult users but gave negative results with children having Autism. It provoked the initiative-taking ability in them and thus increased their confidence; but at the same time it caused them to clash and wrestle over their turns. Third, the authors discovered that participating children tended to work in the area close to their position in the entire diamond touch table. This was a constructive move by them, in terms of collaborative work.

\section{ECHOES SERIOUS GAME}

The ECHOES project is fundamentally an effective user interface developed to cultivate social skills in a child with Autism by letting him play a simple but well-planned game of a sensory garden and an embedded virtual agent, named as Andy [7]. Andy acts as the child's social peer and teaches him lots of healthy communication habits during the play. A noticeable similarity between this UI design and the two discussed earlier is that this design also considered participatory design. It did this in the sense that the learning activities and the virtual agent Andy and his acts were planned and designed with dedicated intervention guidelines. This means that experts in the ASD domain and even the children with ASD participated in the design process by giving recommendations about the features that should be there in the UI.

The ECHOES interface was built according to the SCERTS model that provides Social Communication, Emotional Regulation and Transactional Support - thus the name SCERTS [8].The hardware support of this application was different than the other two projects reviewed. ECHOES avoided a tabletop multi-touch device and utilized a multitouch LCD screen.

As far as the virtual agent, Andy is concerned; it was designed to have special characteristics that the Autistic child could enjoy. Some of his interaction styles were:

Verbal interaction - by saying certain predefined words.

Nonverbal interaction - by pointing, gesturing and changing gazes

Hybrid interaction - both talking and gesturing simultaneously

Apart from these attributes, Andy was made smart enough to represent a well-planned and a near-to-CCI-expertise interface. This is so because Andy had been made responsible enough to exhibit some rather friendly habits, much similar to the ones now seen in many child apps, like the Talking Tom [9]. Some of these habits are laughing upon itching on the screen, seeking attention by special gestures if the child loses interest and doesn't touch the screen for some pre-defined time. These aspects made the project highly commendable in the race of virtual agent based UIs for the treatment of Autism affected children. The project consists of other minute details as well; however, summarizing the focal points, we deduced the following plus points in the ECHOES interface and its virtual agent, Andy:

Users (children who participated in the testing process) were initially hesitant while interacting with Andy; later they became friends with him and many un-communicative children spoke up during these sessions.

Spontaneous social behavior was evoked in the children, as Andy had the ability to grab their attention and ask questions. This enabled the children to enjoying the sessions and unintentionally learning about social communication.
The teachers and trainers of these children, while noticing their interactions with Andy, were glad to mention that there was a noticeable change in the child's behavior and many children who usually did not greet their teachers had now started doing that.

Temperament of children with ASD was kept under control by not setting fixed goals and rather keeping the game free play. This gave the child liberty that we did not find in the other two UIs reviewed. This liberty yielded optimistic results in the context of the child's social skills.

\section{Findings \& Conclusion}

This review intended to investigate some consummate piece of research work done to provide better treatment for Autism. Three different application UIs were analyzed that targeted three different social impairments; namely, communication skills, collaborative skill and social interaction. The reviewed UIs were specialized ones, with out-and-out features for treatment of these impairments. We have tracked down the success factors of these interfaces and in the quest, found out that one characteristic was similar in all three works. This was their interface design methodology. All three groups of researchers implemented the iterative participatory design technique, since the applications were meant to be for Autistic users; thus they needed to be highly CCI-based. After keen observation of the recommendations and experiences of these researchers, we have jotted down points that would act as worthy future directions for us and other interface designers who wish to work for treating the above-discussed Autism impairments via multi-touch software interventions.

\section{REFERENCES}

[1] Sitdhisanguan, K., Dechaboon, A., Chotikakamthorn, N., \& Out, P. (2007, October). Comparative study of WIMP and tangible user interfaces in training shape matching skill for autistic children. In TENCON 20072007 IEEE Region 10 Conference (pp. 1-4). IEEE.

[2] Rapin, I., \& Tuchman, R. F. (2008). Autism: definition, neurobiology, screening, diagnosis. Pediatric Clinics of North America, 55(5), 1129-1146.

[3] Higgins, S. E., Mercier, E., Burd, E., \& Hatch, A. (2011). Multi-touch tables and the relationship with collaborative classroom pedagogies: A synthetic review.International Journal of Computer-Supported Collaborative Learning, 6(4), 515-538.

[4] Wadhwa, B., \& Jianxiong, C. C. (2013, September). Collaborative tablet applications to enhance language skills of children with autism spectrum disorder. In Proceedings of the 11th Asia Pacific Conference on Computer Human Interaction (pp. 39-44). ACM.

[5] Porayska-Pomsta, K., Frauenberger, C., Pain, H., Rajendran, G., Smith, T., Menzies, R., \& Lemon, O. (2012). Developing technology for autism: an interdisciplinary approach. Personal and Ubiquitous Computing, 16(2), 117-127.

[6] Rick, J., Harris, A., Marshall, P., Fleck, R., Yuill, N., \& Rogers, Y. (2009, June). Children designing together on a multi-touch tabletop: an analysis of spatial orientation and user interactions. In Proceedings of the 8th International Conference on Interaction Design and Children (pp. 106-114). ACM. 
[7] Bernardini, S., Porayska-Pomsta, K., \& Smith, T. J. (2014). ECHOES: An intelligent serious game for fostering social communication in children with autism. Information Sciences, 264, 41-60.

[8] Prizant, B. M., Wetherby, A. M., Rubin, E., \& Laurent, A. C. (2003). The SCERTS Model: A Transactional, Family- Centered to Enhancing
Communication and Socioemotional Abilities of Children With Autism Spectrum Disorder. Infants \& Young Children, 16(4), 296-316.

[9]

Outfit7,https://play.google.com/store/apps/details?id=co m.outfit7.talkingtom\&hl=en [Last accessed: 30-032015]. 